\title{
Effect of the DGAT1 K232A genotype of dairy cows on the milk metabolome and proteome
}

\author{
Jing Lu, ${ }^{*} † \ddagger$ Sjef Boeren, $\dagger$ Toon van Hooijdonk, ${ }^{*}$ Jacques Vervoort, $†$ and Kasper Hettinga*1 \\ *Dairy Science and Technology, FQD group, Wageningen University, Bornse Weilanden 9, 6708 WG, Wageningen, the Netherlands \\ †Laboratory of Biochemistry, Wageningen University, Dreijenlaan 3, $6703 \mathrm{HA}$, Wageningen, the Netherlands \\ łInstitute of Agro-Products Processing Science and Technology, Chinese Academy of Agricultural Sciences (CAAS), Beijing, China 100193
}

\section{ABSTRACT}

Diglyceride O-acyltransferase 1 (DGAT1) is the enzyme that catalyzes the synthesis of triglycerides from diglycerides and acyl-coenzyme A. The DGAT1 K232A polymorphism was previously shown to have a significant influence on bovine milk production characteristics (milk yield, protein content, fat content, and fatty acid composition). The mechanism of this influence has, however, not been elucidated. In this study, metabolomics ( ${ }^{1} \mathrm{H}$-nuclear magnetic resonance) and proteomics (laser chromatography-tandem mass spectrometry) were applied to determine the serum and lipid metabolite composition and milk fat globule membrane proteome of milk samples from cows with the DGAT1 KK and AA genotypes. The milk samples from cows with the DGAT1 KK genotype contained more stomatin, sphingomyelin, choline, and carnitine, and less citrate, creatine or phosphocreatine, glycerolphosphocholine, mannose-like sugar, acetyl sugar phosphate, uridine diphosphate (UDP)-related sugar, and orotic acid compared with milk samples from cows with the DGAT1 AA genotype. Based on these results, we propose that the differences between the DGAT1 genotypes may be related to stomatin-sphingomyelin lipid rafts as well as structural (cell membrane) differences in epithelial cells of the mammary gland. In conclusion, our study shows that, in addition to previously described changes in triglyceride composition, cows differing in DGAT1 polymorphism differ in their milk proteome and metabolome, which may help in further understanding the effect of the DGAT1 K232A polymorphism on milk production characteristics.

Key words: proteomics, metabolomics, DGAT1 polymorphism, milk synthesis

Received September 18, 2014.

Accepted January 30, 2015.

${ }^{1}$ Corresponding author: kasper.hettinga@wur.nl

\section{INTRODUCTION}

Fat is a major constituent of milk. It varies from less than $2 \%$ in horse milk to more than $50 \%$ in fur seal milk (Walstra et al., 2006). Bovine milk contains about 1 to $10 \%$ fat, of which $98 \%$ is triglycerides (Walstra et al., 2006). Triglycerides are mainly synthesized from diglycerides in the mammary gland, which is a committed step in the whole triglycerides synthesis process. The enzyme catalyzing this step is diglyceride O-acyltransferase (DGAT); DGAT1 is 1 of 2 isoforms (DGAT1 and DGAT2) of DGAT in both cows and other mammals. It is known that DGAT1 plays a crucial role in milk production, because DGAT1-knockout mice are unable to produce milk and almost no lipid droplets accumulate in the secretion region of the mammary gland in these mice (Smith et al., 2000). Cases et al. (1998) identified the K232A polymorphism in the bovine DGAT1 gene. This polymorphism was shown to have a significant effect on bovine milk production and milk characteristics. It was also shown that the DGAT1 polymorphism significantly influenced milk FA composition (Schennink et al., 2007). The DGAT1 K polymorphism was found to associate with a higher fat percentage, higher fat yield, higher protein percentage, lower protein yield, and lower milk yield (Grisart et al., 2002; Schennink et al., 2007). Many studies have investigated the effect of DGAT1 polymorphism on milk production, with a focus on fat production (e.g., in different cow breeds; Berry et al., 2010; Cardoso et al., 2011; Komisarek et al., 2011; Molee et al., 2012). In addition, a recent paper by Argov-Argaman et al. (2013) described the effect of the DGAT1 genotype and fat content on the composition of the milk fat globule membrane (MFGM). However, the mechanism behind the association between DGAT1 polymorphism and milk synthesis is unclear. In the current paper, advanced proteomics and metabolomics techniques were applied to further elucidate this mechanism.

Proteins in butter serum, which are enriched in MFGM proteins, from cows with different DGAT1 polymorphisms (KK and AA) were analyzed by using advanced proteomics techniques (filter-aided samples 
preparation coupled with dimethyl labeling and nanoLCOrbitrap-MS/MS; Thermo Electron, San Jose, CA). This MFGM is a 3-layer membrane that covers milk fat globules in milk. Proteins in MFGM are considered representative of epithelial cells because of their specific origin (endoplasmic reticulum membrane, cytoplasm, and apical plasma membrane of epithelial cells; McManaman and Neville, 2003). Many milk synthesis and secretion proteins have been identified in MFGM ( $\mathrm{Lu}$ et al., 2011). The differences in MFGM proteins between cows may thus reflect differences in the epithelial cells of the mammary glands between cows. In addition to MFGM protein analysis, also the lipid composition and serum metabolites of the selected milk samples were analyzed by ${ }^{1} \mathrm{H}$-nuclear magnetic resonance (NMR). The benefits of combining metabolome and proteome data to understand the mammary gland physiology of dairy cows has recently been shown for negative energy balance (Lu et al., 2013). In the present study, the same approach of combining milk metabolome and proteome data was used to investigate the physiological changes in the mammary gland of cows differing in DGAT1 polymorphism, to better understand the effect of this polymorphism on milk synthesis.

\section{MATERIALS AND METHODS}

\section{Sample Selection}

Bovine milk samples were selected according to DGAT1 polymorphisms (KK or AA) and fat content (3-4, 4-5, and 5-6\%) from the Dutch Milk Genomics Initiative (Wageningen, the Netherlands) biobank of 1,918 cows. Eight to 10 cows were selected for each genotype and milk fat content, resulting in milk samples of 55 cows for further analysis. As described by Schennink et al. (2007), genotyping of DGAT1 polymorphisms was performed using a Taqman allelic discrimination method in an Applied Biosystems 7500 Real-Time PCR System (Applied Biosystems, Foster City, CA) on DNA isolated from blood samples of selected cows. Fat percentage of each milk sample was measured by using a MilkoScan FT6000 (Foss Electric, Hillerød, Denmark) at the Milk Control Station (Zutphen, the Netherlands).

\section{GC Analysis for FA Composition}

Milk FA data reported in this paper are a subset of the data described by Schennink et al. (2007). Briefly, FAME were prepared from fat extract according to ISO Standard 15884 (ISO-IDF, 2002b) followed by analysis gas chromatographic separation according to ISO standard 15885 (ISO-IDF, 2002a) at COKZ laboratory (Netherlands Controlling Authority for Milk and Milk Products, Leusden, the Netherlands). Peaks were identified and quantified using pure methyl esters (Sigma-Aldrich, Zwijndrecht, the Netherlands; Larodan, Malmö, Sweden). Student's $t$-test was applied to compare FA concentration between both genotypes, including all fat content groups per genotype $(P<0.05)$.

\section{${ }^{1}$ H-NMR Metabolomics Analysis}

Milk Lipid Metabolome. For milk lipid metabolome analysis, as described in Lu et al. (2013), $400 \mu \mathrm{L}$ of whole milk was added to $600 \mu \mathrm{L}$ of deuterated chloroform and vortexed thoroughly in an Eppendorf tube. The mixture was centrifuged at 20,000 $\times g$ for $30 \mathrm{~min}$ at room temperature. Then, $200 \mu \mathrm{L}$ of the deuterated chloroform phase (bottom liquid phase) was used for ${ }^{1} \mathrm{H}-\mathrm{NMR}$ analysis (Bruker $600 \mathrm{MHz}$ Avance III NMR spectrometer equipped with a CryoPlatform cryogenic cooling system, a BCU-05 cooling unit, and an ATM automatic tuning and matching unit; Bruker Biospin, Rheinstetten, Germany). The samples were measured in 3-mm NMR tubes (Bruker matching system). Measurements were performed at a temperature of $300 \mathrm{~K}$. Identification of the different lipid molecules was based on Tukiainen et al. (2008), Vinaixa et al. (2010) and Prema et al. (2013). To confirm identification of metabolites, as well as check for possible overlapping metabolites in the ${ }^{1} \mathrm{H}-\mathrm{NMR},{ }^{1} \mathrm{H}-{ }^{1} \mathrm{H}$ (correlation spectroscopy, total correlation spectroscopy), and ${ }^{1} \mathrm{H}-{ }^{13} \mathrm{C}$ (heteronuclear single-quantum correlation spectroscopy, heteronuclear multiple-bond correlation spectroscopy) 2-dimensional NMR spectra were used.

Milk Serum Metabolome. As described in Lu et al. (2013), polar metabolites were obtained from the deuterated chloroform samples (see previous) by taking $100 \mu \mathrm{L}$ of the upper liquid water phase, mixing it with $100 \mu \mathrm{L}$ of phosphate buffer, transferring into a 3-mm NMR tube, and measuring in the same NMR spectrometer at $300 \mathrm{~K}$. Baseline corrections and zero alignment were performed manually for all spectra. The Nuclear Overhauser effect spectroscopy (NOESY) and J-resolved (JRES) spectra were obtained for all milk serum samples and calibrated to the internal standard, trimethylsilyl propionate $(\delta=0.00 \mathrm{ppm})$. The JRES data analysis was done according to Fonville et al. (2010). Spectral binning was applied to integrate NOESY spectra with window size of $0.02 \mathrm{ppm}$ (van der Hooft et al., 2011).

Data Analysis. Statistical analysis of data was performed using the free access software MultiExperiment Viewer (http://www.tm4.org/mev.html). The data was transformed by calculating the $\log _{2}$ for the ratio of concentration over the median of each compound. 
Significant differences were calculated by Student's $t$ test $(P<0.05)$.

\section{Proteomics Analysis}

Separation of Butter Serum from Whole Milk. One hundred milliliters of milk sample was heated to $27^{\circ} \mathrm{C}$ in a water bath. Five milliliters of $\mathrm{HCl}(4 M)$ was added to the milk sample and the sample was shaken for $45 \mathrm{~min}$ until the fat was clearly separated. The water phase was discarded and the fat phase was washed with Milli-Q water (Millipore, Billerica, MA). The fat phase was then heated in the oven at $70^{\circ} \mathrm{C}$ for $30 \mathrm{~min}$. Milli-Q water was added to the fat phase $(1: 1, \mathrm{vol} /$ vol) and the sample was heated in the oven at $70^{\circ} \mathrm{C}$ for another $15 \mathrm{~min}$. Finally, the sample was centrifuged at $1,500 \times g$ for $15 \mathrm{~min}$ at $10^{\circ} \mathrm{C}$. The water phase in the bottom was the buttermilk containing MFGM proteins for further proteomic analysis.

Protein Determination of Butter Serum. In our study, the butter serum samples obtained from the Dutch Milk Genomics Initiative biobank were used to study the MFGM proteome, as it mainly consisted of MFGM proteins. Protein concentration of butter serum was determined using the Dumas method with a NA 2100 Protein nitrogen analyzer (CE Instruments, Milan, Italy).

Experimental Design. In our study, the MFGM proteome of 2 samples could be directly compared in a single proteomics analysis due to the use of different isotope labels (heavy and light), as will be explained herein. To obtain the most information of the effect of DGAT1 polymorphisms (KK and AA) on the MFGM proteome, 4 comparisons were performed (Table 1).

The $\mathrm{K}$ polymorphism of DGAT1 is normally associated with higher fat content in milk than the A polymorphism of DGAT1 (Schennink et al., 2007). The milk samples from DGAT1 KK cows with its average fat content (5-6\%) were thus compared with the milk samples from DGAT1 AA cows with its normal average fat content (3-4\%; Schennink et al., 2007). However, besides the DGAT1 polymorphism, fat content may also influence the metabolome or the MFGM proteome. Milk samples with the same fat content (4-5\%) from DGAT1 KK and AA cows were therefore compared to eliminate the influence of fat content on MFGM protein composition. Finally, to see the influence of fat content on the MFGM proteome without interference of DGAT1 polymorphisms, a separate comparison in DGAT1 AA and KK cows was done between milk samples with 5 to 6 and 3 to $4 \%$ fat. In each comparison, pooled butter serum samples were used (4-5 butter serum samples/ pool). All the comparisons were done in both biological and technical duplicates. A 2-fold change in protein abundance was used as significance cut-off in the quantitative proteomics analysis (Lu et al., 2011).

Filter-Aided Sample Preparation-Dimethyl Labeling-nanoLC-Orbitrap-MS/MS. The method used to prepare butter serum samples for LC-MS/ MS analysis was based on filter-aided sample preparation (Wiśniewski et al., 2009) and dimethyl labeling (Boersema et al., 2009). Then, the prepared samples were analyzed using nanoLC-Orbitrap-MS/MS. The detailed procedures were described in Lu et al. (2011).

Data Analysis. Each run with all MS/MS spectra was analyzed using MaxQuant 1.1.1.36 with Andromeda as peptide search engine (Cox and Mann, 2008; Cox et al., 2011). The database for peptide or protein searches was a concatenated IPI bovine database (ftp://ftp.ebi.ac.uk/pub/databases/IPI/last_release/ current/) with reverse sequences (for determining the false discovery rate) generated by MaxQuant. The contaminants database of MaxQuant was also used for peptide or protein searches, which includes sequences of trypsin and human keratins. Identification and quantification of proteins were simultaneously performed in MaxQuant. Carbamidomethylated cysteines were set as fixed modification; oxidation of methionine as well as N-terminal acetylation and deamidation of asparagine or glutamine were set as variable modification for both identification and quantification. Mass deviation of $0.5 \mathrm{Da}$ was set as the maximum allowed for MS/ MS peaks, and a maximum of 2 missed cleavages were allowed. Maximum false discovery rates were set to $1 \%$ on both peptide and protein level. Minimum required peptide length was 6 amino acids for both identification and quantification. A minimum of 2 peptides, 1 unique peptide for each protein, were required for identification. Dimethyl labeling was set as doublets with dimethLys0 and dimethNter0 as light and dimethLys4

Table 1. Four comparisons performed in proteomics analysis; diglyceride O-acyltransferase 1 (DGAT1) polymorphisms: KK and AA; milk fat content: 3 to 4,4 to 5 , and 5 to $6 \%^{1}$

\begin{tabular}{lcccc}
\hline Factor & $\begin{array}{c}\text { Polymorphism } \\
\text { and fat content }\end{array}$ & Polymorphism & $\begin{array}{c}\text { Fat content } \\
\text { in KK }\end{array}$ & $\begin{array}{c}\text { Fat content } \\
\text { in AA }\end{array}$ \\
\hline Heavy dimethyl label & $5-6 \%$ KK & $4-5 \%$ KK & $5-6 \%$ KK & $5-6 \%$ AA \\
Light dimethyl label & $3-4 \%$ AA & $4-5 \%$ AA & $3-4 \%$ KK & $3-4 \%$ AA \\
\hline
\end{tabular}

${ }^{1}$ Each sample in the comparison is pooled milk from 4 to 5 cows. 
and dimethNter4 as heavy. Razor and unique peptides were used for quantification. Normalized heavy-to-light ratios were used for further statistical analysis. Only proteins that were differently regulated in both biological replicates were reported as being significantly different.

\section{RESULTS}

\section{Milk FA Composition}

Fatty acids composition of all selected milk samples was previously analyzed by GC and 27 FA were quantified [Schennink et al. (2007) describes the data for all 2,000 cows, from which the 55 cows for this experiment were taken]. Significantly changed FA between DGAT1 KK and AA cows are shown in Table 2. Milk from DGAT1 AA cows had relatively more short- and medium-chain FA (C4-C14), whereas more long-chain FA were observed in milk from DGAT1 KK cows. Energy provided by FA depends on the amount of carbons molecules (Doreau and Ferlay, 1994). Carbon per mole of milk fat was therefore calculated to see if variation existed in energy content of milk fat between genotypes. Although differences in the FA composition were noted, the total amount of milk FA carbons in $1 \mathrm{~mol}$ of milk fat of DGAT1 KK and AA cows was not different (13.9 $\mathrm{mol}$ of carbon $/ \mathrm{mol}$ of fat), which indicates that the energy content of milk fat does not differ between genotypes.

\section{Milk Lipid and Serum Metabolome}

Figure 1 shows an example of an NMR spectrum of the milk lipids, including the peak assignment used for identification. The results of the ${ }^{1} \mathrm{H}-\mathrm{NMR}$ analysis of milk lipids showed that sphingomyelin and CLA were significantly higher in milk samples from DGAT1 KK cows (Table 3). The amount of CLA in milk was also calculated according to the GC analysis. The results of the ${ }^{1} \mathrm{H}-\mathrm{NMR}$ analysis were in agreement with the GC analysis with regard to difference between genotypes and variation within genotypes. However, due to slightly larger differences between genotypes in the NMR data, the $P$-values were slightly lower, resulting in CLA only being significantly different in the ${ }^{1} \mathrm{H}-\mathrm{NMR}$ analysis.
The difference in CLA between the AA and KK genotype as determined by ${ }^{1} \mathrm{H}-\mathrm{NMR}$ analysis was the same for all 3 spectral regions used for quantification of CLA.

Of all serum metabolites quantified after the ${ }^{1} \mathrm{H}-\mathrm{NMR}$ analysis, citrate, creatine, or phosphocreatine, glycerolphosphocholine, mannose-like sugar, acetyl sugar phosphate, uridine diphosphate (UDP)-related sugar, and orotic acid were shown to have a higher concentration in milk serum of DGAT1 AA cows compared with KK cows. In milk serum of DGAT1 KK cows, choline and carnitine were shown to have a higher concentration (Table 4). No difference was observed in other milk serum metabolites of DGAT1 KK and AA cows.

\section{Milk Fat Globule Membrane Proteome}

In total, 249 proteins were identified and quantified in butter serum. The full proteomics data set is available in Supplementary Table S1 (http://dx.doi. org/10.3168/jds.2014-8872). As expected, the major proteins of MFGM (butyrophilin, xanthine dehydrogenase or oxidase, lactadherin, perilipin-2, and CD36) were all identified in butter serum in a relatively high amount compared with the other proteins. The differences in proteome for the 4 comparisons are shown in Figure 2. Milk samples of DGAT1 KK cows always contained a higher amount of stomatin than milk samples of DGAT1 AA cows (Figure 2A and B). However, the amount of stomatin in MFGM is not influenced by fat content (Figure 2C and D). Stomatin is a protein consisting of 289 amino acids. The amino acid sequence and the peptides detected in our study are shown in Figure 3.

The number of proteins which differ between samples with the same DGAT1 genotype, but different fat content is higher in AA cows (7) than in KK cows (0; Figure 2D and C, respectively). There was no change of MFGM proteins with increasing fat content for DGAT1 KK cows (Figure 2C), as well as no common protein that changed with increasing fat content within both DGAT1 KK and AA cows (Figure 2C and D).

\section{DISCUSSION}

In the current study, we applied metabolomics and proteomics techniques to understand the effect of

Table 2. Significant differences in FA in milk samples from diglyceride O-acyltransferase 1 (DGAT1) KK and AA cows (KK 3-6\% fat, 28 samples; AA 3-6\% fat, 27 samples) in percent of total fat (g/100 g)

\begin{tabular}{lccccccccc}
\hline Item & C10:0 & C12:0 & C14:0 & C4:0-C14:0 & C15:0 & C16:1 & C17:0 & C18:0 & $\begin{array}{c}\text { C18:1 } \\
\text { trans-11 }\end{array}$ \\
\hline KK & 2.78 & 3.68 & 10.86 & 24.87 & 1.19 & 1.54 & 0.48 & 9.56 & 0.87 \\
AA & 3.03 & 4.18 & 11.92 & 26.47 & 1.08 & 1.32 & 0.44 & 8.73 & 0.70 \\
\hline
\end{tabular}




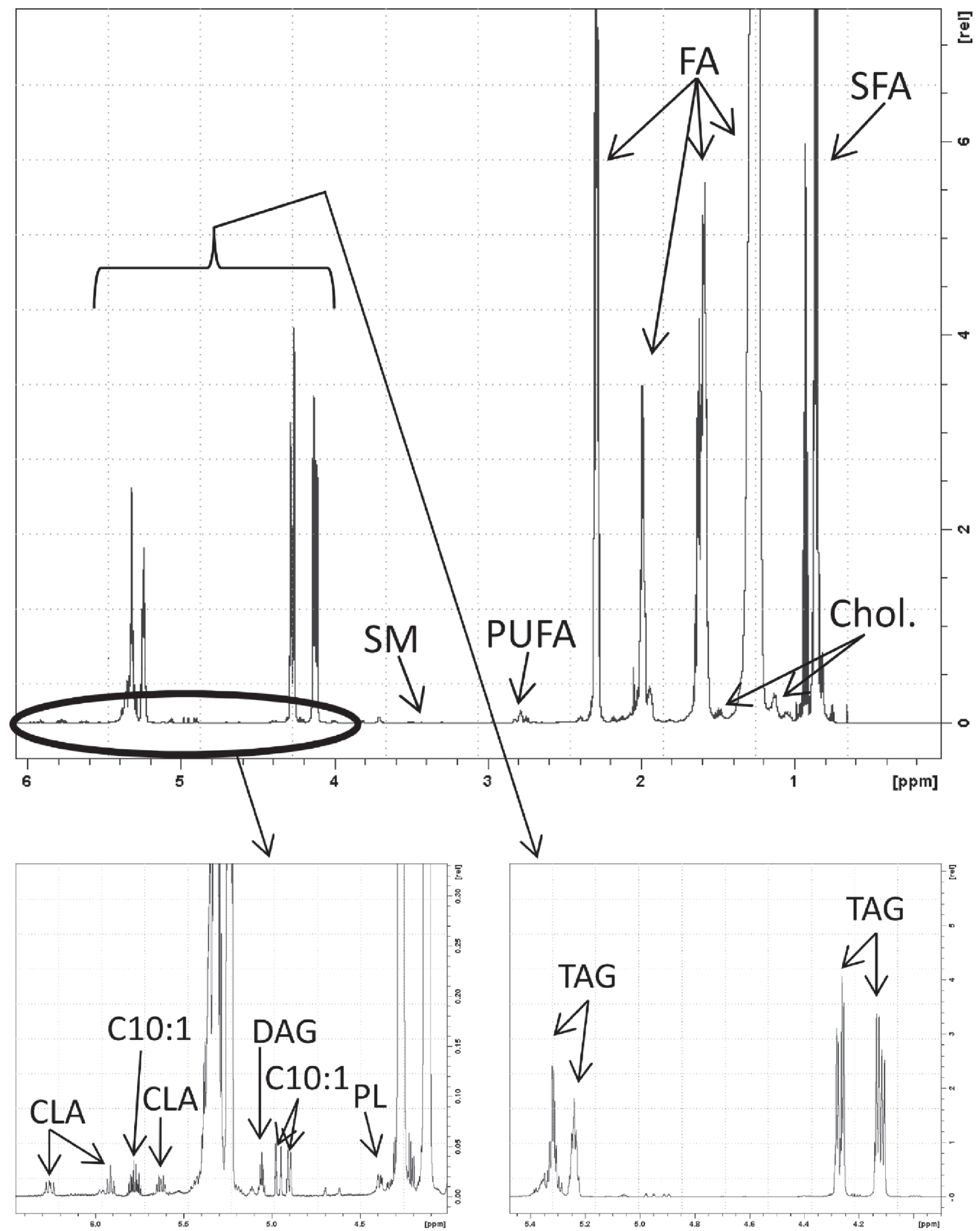

Figure 1. Example of a nuclear magnetic resonance spectrum for the milk lipids, including peak assignment used for identification [based on Tukiainen et al. (2008), Vinaixa et al. (2010), and Prema et al. (2013)]. Chol. = cholesterol; DAG = diacylglycerol; SM = sphingomyelin; $\mathrm{TAG}=$ triacylglycerol. 
Table 3. Significantly changed milk lipids between diglyceride O-acyltransferase 1 (DGAT1) AA and KK cows ${ }^{1}$

\begin{tabular}{lrr}
\hline Item & CLA (6.25) & \multicolumn{1}{c}{ SM (3.43) } \\
\hline AA & $-0.05 \pm 0.23$ & $-0.04 \pm 0.20$ \\
KK & $0.20 \pm 0.42$ & $0.15 \pm 0.29$ \\
\hline
\end{tabular}

${ }^{1}$ Data were the average $\log _{2}$ for the ratio of concentration over median of each compound of all tested samples $\pm \mathrm{SD} .{ }^{1} \mathrm{H}-\mathrm{NMR}$ chemical shift (in ppm) between parentheses. Significant differences were calculated by unpaired Student's $t$-test. Sample names reflect genetic polymorphism $(\mathrm{AA} / \mathrm{KK}) . \mathrm{SM}=$ sphingomyelin.

DGAT1 polymorphism in dairy cows on milk synthesis, showing differences in milk serum metabolites (choline, carnitine, citrate, creatinine, glycerol-phosphocholine, orotic acid, and several sugars), triglyceride composition, and milk fat globule membrane (stomatin, sphingomyelin) between genotypes. Metabolomics data of both the lipid and serum fraction were collected. One of the most remarkable results of these analyses was that several metabolites were detected that were not expected to be present in milk because of their subcellular location during milk synthesis, such as acetyl sugar phosphate and UDP-sugars. They are intermediates in different biological pathways that occur in cell cytosol. The higher concentration of these intermediates in the milk of DGAT1 AA cows could indicate leakage of cellular components to milk or higher permeability of cell membrane in the epithelial cells of mammary glands in these cows. The leakage of cellular components and permeability of cell membrane could be associated with the differences in the epithelial cell membrane stability. However, more in-depth elucidation of the exact processes taking place is needed.

In addition, carnitine was shown to have a higher concentration in DGAT1 KK cows. Carnitine is known to be involved in long-chain FA metabolism, where it is needed for transport of these FA before oxidation (Steiber et al., 2004). This change in carnitine may be related to both the cow's metabolism (Erfle et al., 1974) and the calf's need for carnitine to metabolize the long-chain FA from milk (Lamhonwah et al., 2011).

Similar to our data reported in Table 2, Schennink et al. (2007) also observed that DGAT1 AA was associated with a higher amount of FA shorter than C16 and a lower amount of C18 in a population of 1,918 cows, which was expected because our 55 samples were a subset from the 1,918 cow samples by Schennink et al. (2007). In addition, the total amount of milk fat carbon in $1 \mathrm{~mol}$ of fat was not different between milk samples from DGAT1 KK and AA cows, implying that the total energy in $1 \mathrm{~mol}$ of milk fat is the same in DGAT1 KK and AA cows.

Due to the specific origin of MFGM proteins, they are considered representative of the secretory cells in mam-

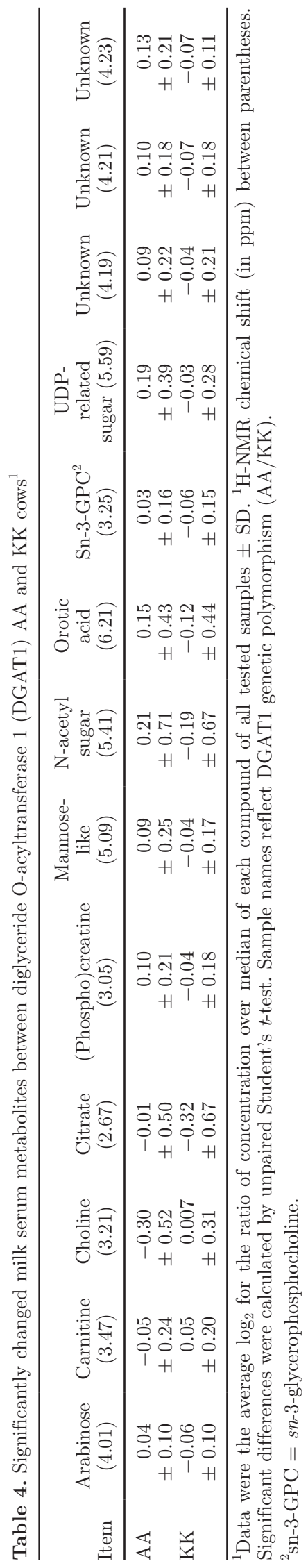

Journal of Dairy Science Vol. 98 No. 5, 2015 

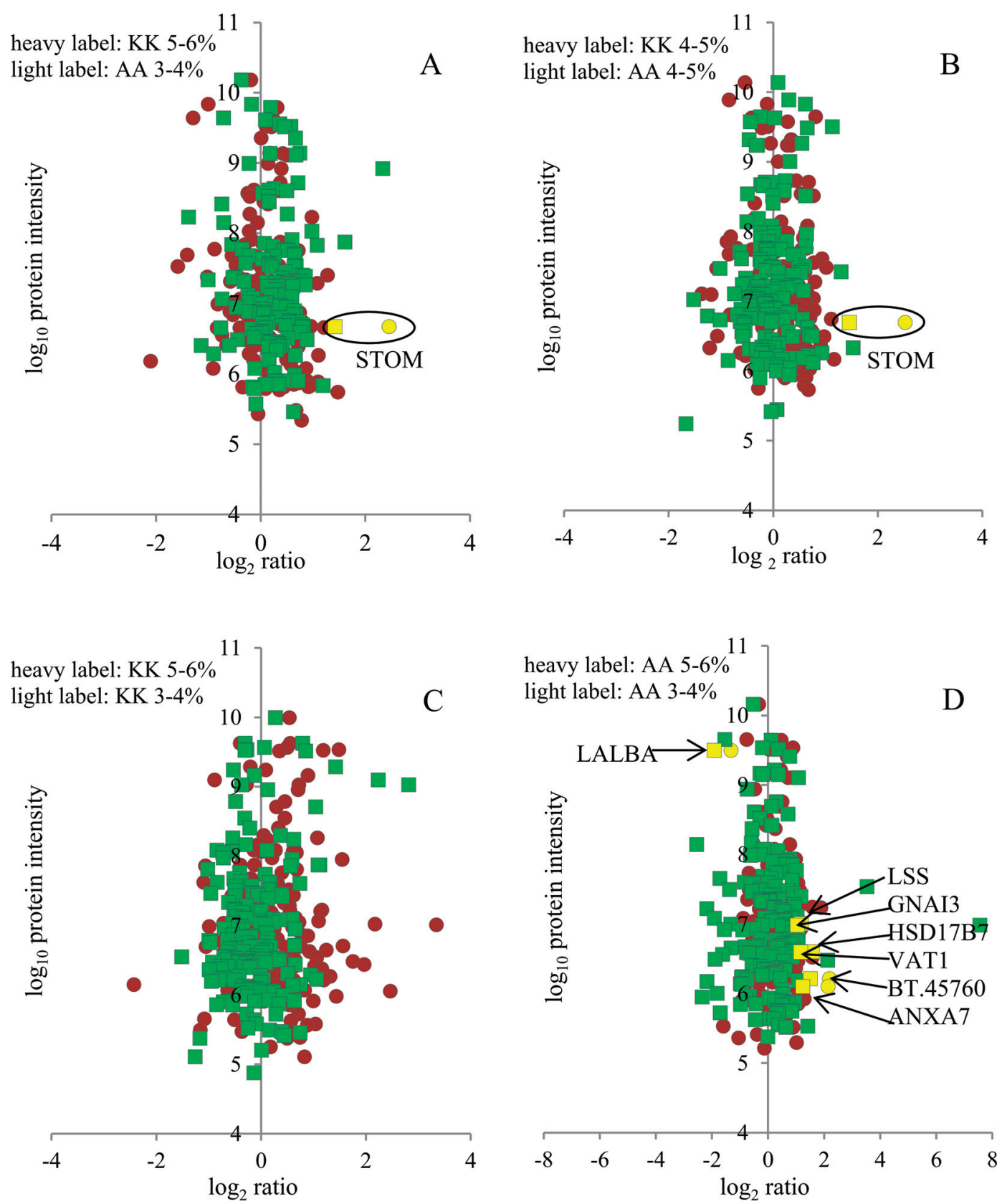

Figure 2. Comparison of proteins in butter serum from cows with different diglyceride O-acyltransferase 1 (DGAT1) polymorphisms and different fat contents by quantitative proteomics analysis, with the specific comparison mentioned in the top left corner of each figure. For each protein, $\log _{2}$-normalized protein ratios (average of technical replicates) are plotted against average $\log _{10}$ protein intensity. Proteins on the left were upregulated in sample with the light label; proteins on the right were upregulated in cows with the heavy label. Gray (green) square $=$ biological replicate 1; black (red) dot = biological replicate 2; white (yellow) dot or square = proteins that change more than 2-fold in both biological replicates, with the gene name; STOM = stomatin; LALBA $=\alpha-\mathrm{LA}$; LSS = lanosterol synthase; GNAI3 = guanine nucleotide binding protein (G protein), $\alpha$-inhibiting activity polypeptide 3; HSD17B7 = HSD17B7 protein; VAT1 = VAT1 protein; ANXA7 = annexin A7; BT. $45760=$ transcribed locus BT.45760. Color version available online.

mary gland and were therefore chosen as study material. By using proteomic techniques, 249 proteins were identified and quantified in MFGM-enriched butter serum including a wide range of low-abundant proteins. Variation between biological replicates, as shown in Figure 2, was larger than variation between technical replicates (data not shown), indicating that the variation shown in Figure 2 is real biological variation between the biological replicates. The proteomics analyses also showed that as milk fat content increased (from 3-4 to 5-6\%), 


\title{
MSDKRPAVDTQARRLPDSFKDSPSTGLGVCGWILVAVSFLFTVITFPVSIWMCIKIIKE
}

\author{
YERAIIFRLGRILQGGAKGPGLFFILPCTDSFIKVDMRTISFDIPPQEILTKDSVTISVD \\ GVVYYRVQNATLAVANITNADSATRLLAQTTLRNVLGTKNLSQILSDREEIAHNMQ
}

\section{CTLDDATDDWGIKVERVEIKDVKLPVQLQRAMAAEAEASREARAKVIAAEGEMN}

\section{ASRALKEASMVITESPAALQLRYLQTLTTIAAEKNSTIIFPLPIDMLQAIMGPKQ}

Figure 3. Amino acid sequence of stomatin. Peptides in bold were identified and quantified in this study.

the MFGM proteome changed less in DGAT1 KK cows than that in DGAT1 AA cows, as visible in the larger $\log _{2}$ ratios in both biological replicates (Figure 2B vs. D). The same was observed for FA composition, which did not differ as much between KK cows as between AA cows (data not shown). Furthermore, stomatin was the only protein that was clearly different between milk samples from DGAT1 KK and AA cows. It was found that in human stomatin, Cys-30 (a cysteine amino acid residue that is also present in bovine stomatin) was palmitoylated. This palmitoylation of the protein was assumed to lead to the increased affinity of this protein to plasma membrane (Snyers et al., 1999). Because of this posttranslational modification, the peptides containing Cys-30 could not be identified in the current proteomic analysis (Figure 3), as the resulting peptide becomes too hydrophobic for easy ionization using electrospray. However, 7 peptides were observed and quantified in our experiments with at least 2 peptides quantified for each comparison, which ensured a good accuracy of the protein ratio calculation. To our knowledge, no research has been done on the function of stomatin in secretory cells in the mammary gland. Stomatin is a protein that was first identified in the membrane of erythrocytes (Snyers et al., 1999), and was ubiquitously expressed in vertebrate tissues and different cell lines (Umlauf et al., 2004). Stomatin was also shown to be a scaffolding component in lipid rafts (also known as lipid microdomains) and expressed mainly in plasma membrane. It was suggested to play an important structural role in lipid raft formation (Salzer and Prohaska, 2001; Umlauf et al., 2004). In addition, stomatin is suggested to be involved in cytoskeleton formation and ion transport across the cell membrane (Snyers et al., 1997, 1999).

The amount of sphingomyelin was found to be significantly higher in milk samples from DGAT1 KK cows, which corresponds with Argov-Argaman et al. (2013). Sphingomyelin is a major component of cell membranes. In milk, sphingomyelin is mainly located in MFGM. Sphingomyelin is, together with phosphatidylcholine, 1 of the 2 major phospholipids in MFGM.
It accounts for approximately $25 \%$ of phospholipids in bovine milk (Palmquist et al., 2006). Sphingomyelin is synthesized from phosphatidylcholine, and is an important source of choline in milk (Holmes-McNary et al., 1996). Glycerophosphocholine, which is as alternative route in the choline metabolism and is also synthesized from phosphatidylcholine, was decreased in cows with the AA genotype, whereas sphingomyelin increased (Tables 3 and 4). Increased synthesis of sphingomyelin may lead to lower levels of glycerophosphocholine in milk due to reduced phosphatidylcholine, the joint precursor of both molecules. Recently, researchers observed that sphingomyelin was located in lipid rafts, a liquid-ordered domain, of MFGM, whereas other glycerophospholipid were present in liquid-disordered domains (Lopez et al., 2010; Lopez and Menard, 2011).

Both stomatin and sphingomyelin have previously been shown to be important components of lipid rafts in membrane systems, and both were present in higher concentration in MFGM of DGAT1 KK cows. We therefore hypothesized that more stomatin-sphingomyelin lipid rafts were present in MFGM of DGAT1 KK cows. Furthermore, only stomatin, instead of calveolins and flotillins that are normally occurring scaffolding proteins in lipid rafts, was observed in bovine MFGM. This could imply that stomatin is the main, or perhaps only, scaffolding protein in MFGM lipid rafts. As MFGM is derived from the outer leaflet of the endoplasmic reticulum membrane and the double-layer of apical plasma membrane from mammary epithelial cells, this could imply that the epithelial cell membranes of DGAT1 KK cows contain more stomatin-structured lipid rafts. In a recent study, cows during negative energy balance were also shown to have more stomatin-structured lipid rafts in MFGM, which could influence the milk secretion during that period (Lu et al., 2013). Huttner and Zimmerberg (2001) considered that membrane budding and fission was strongly influenced by lipid raft formation around a nascent bud. Moreover, McManaman and Neville (2003) suggested that lipid droplets were secreted from epithelial cells in a budding pro- 
cess through the apical plasma membrane. Stomatinsphingomyelin lipid rafts may thus have an important role in lipid droplet budding from plasma membrane to the alveolar lumen. It was previously shown that the DGAT1 enzyme from cows with the $\mathrm{K}$ polymorphism has a significantly larger maximal velocity in producing triglycerides, which leads to a relatively higher fat content in milk (Grisart et al., 2004). The higher amount of stomatin-sphingomyelin lipid rafts could help cope with efficient lipid droplet budding from epithelial cells to milk in DGAT1 KK cows. However, further elucidation of the localization and function of lipid rafts and its composition in and on epithelial cells is needed.

The effect of the DGAT1 K232A polymorphism has only been studied in relation to milk compositional parameters; however, the polymorphism of DGAT1 will be the same throughout the whole cow. Thus, if the DGAT1 $\mathrm{K}$ and A enzyme have preference for different FA during triglyceride synthesis, the same effects as shown in milk should also be true in other lipid-metabolizing organs in cows. Therefore, the FA composition of other lipid fractions, such as blood and adipose tissue, could be different between cows with different DGAT1 polymorphisms.

\section{CONCLUSIONS}

The data shown in our paper suggest that stomatinsphingomyelin lipid rafts, as well as the membrane organization or cell structure of epithelial cells in mammary glands, could be different between DGAT1 KK and AA cows. This difference in cell architecture may influence the milk composition and milk (fat) synthesis. In addition, as shown before, DGAT1 $\mathrm{K}$ seems to prefer long-chain FA, whereas DGAT1 A seems to prefer short- and medium-chain FA. These observations, especially with regard to the difference in membrane structure, could provide a new direction for further understanding of the mechanisms by which the DGAT1 K232A polymorphism influences milk synthesis.

\section{REFERENCES}

Argov-Argaman, N., K. Mida, B. C. Cohen, M. Visker, and K. Hettinga. 2013. Milk fat content and DGAT1 genotype determine lipid composition of the milk fat globule membrane. PLoS ONE 8:e68707.

Berry, D. P., D. Howard, P. O'Boyle, S. Waters, J. F. Kearney, and M. McCabe. 2010. Associations between the K232A polymorphism in the diacylglycerol-O-transferase 1 (DGAT1) gene and performance in Irish Holstein-Friesian dairy cattle. Ir. J. Agric. Food Res. 49:1-9.

Boersema, P. J., R. Raijmakers, S. Lemeer, S. Mohammed, and A. J. R. Heck. 2009. Multiplex peptide stable isotope dimethyl labeling for quantitative proteomics. Nat. Protoc. 4:484-494.

Cardoso, S. R., L. B. Queiroz, V. A. Goulart, G. B. Mourão, E. Benedetti, and L. R. Goulart. 2011. Productive performance of the dairy cattle Girolando breed mediated by the fat-related genes DGAT1 and LEP and their polymorphisms. Res. Vet. Sci. 91:e107-e112.

Cases, S., S. J. Smith, Y. W. Zheng, H. M. Myers, S. R. Lear, E. Sande, S. Novak, C. Collins, C. B. Welch, A. J. Lusis, S. K. Erickson, and R. V. Farese. 1998. Identification of a gene encoding an acyl CoA: diacylglycerol acyltransferase, a key enzyme in triacylglycerol synthesis. Proc. Natl. Acad. Sci. USA 95:13018-13023.

Cox, J., and M. Mann. 2008. MaxQuant enables high peptide identification rates, individualized p.p.b.-range mass accuracies and proteome-wide protein quantification. Nat. Biotechnol. 26:13671372 .

Cox, J., N. Neuhauser, A. Michalski, R. A. Scheltema, J. V. Olsen, and M. Mann. 2011. Andromeda: A peptide search engine integrated into the MaxQuant environment. J. Proteome Res. 10:1794-1805.

Doreau, M., and A. Ferlay. 1994. Digestion and utilisation of fatty acids by ruminants. Anim. Feed Sci. Technol. 45:379-396.

Erfle, J. D., F. D. Sauer, and L. J. Fisher. 1974. Interrelationships between milk carnitine and blood and milk components and tissue carnitine in normal and ketotic cows. J. Dairy Sci. 57:671-676.

Fonville, J. M., A. D. Maher, M. Coen, E. Holmes, J. C. Lindon, and J. K. Nicholson. 2010. Evaluation of full-resolution J-resolved ${ }^{1} \mathrm{H}$ NMR Projections of biofluids for metabonomics information retrieval and biomarker identification. Anal. Chem. 82:1811-1821.

Grisart, B., W. Coppieters, F. Farnir, L. Karim, C. Ford, P. Berzi, N. Cambisano, M. Mni, S. Reid, P. Simon, R. Spelman, M. Georges, and R. Snell. 2002. Positional candidate cloning of a QTL in dairy cattle: Identification of a missense mutation in the bovine DGAT1 gene with major effect on milk yield and composition. Genome Res. 12:222-231.

Grisart, B., F. Farnir, L. Karim, N. Cambisano, J. J. Kim, A. Kvasz, M. Mni, P. Simon, J. M. Frère, W. Coppieters, and M. Georges. 2004. Genetic and functional confirmation of the causality of the DGAT1 K232A quantitative trait nucleotide in affecting milk yield and composition. Proc. Natl. Acad. Sci. USA 101:2398-2403.

Holmes-McNary, M. Q., W. L. Cheng, M. H. Mar, S. Fussell, and S. H. Zeisel. 1996. Choline and choline esters in human and rat milk and in infant formulas. Am. J. Clin. Nutr. 64:572-576.

Huttner, W. B., and J. Zimmerberg. 2001. Implications of lipid microdomains for membrane curvature, budding and fission . Curr. Opin. Cell Biol. 13:478-484.

ISO-IDF. 2002a. Milkfat-Determination of the Fatty Acid Composition by Gas-liquid Chromatography (ISO 15885-IDF 184). International Dairy Federation, Brussels, Belgium.

ISO-IDF. 2002b. Milkfat-Preparation of Fatty Acid Methyl Esters (ISO 15884-IDF 182). International Dairy Federation, Brussels, Belgium.

Komisarek, J., A. Michalak, and A. Walendowska. 2011. The effects of polymorphisms in DGAT1, GH and GHR genes on reproduction and production traits in jersey cows. Anim. Sci. Pap. Rep. 29:29-36.

Lamhonwah, A. M., L. Mai, C. Chung, D. Lamhonwah, C. Ackerley, and I. Tein. 2011. Upregulation of mammary gland OCTNs maintains carnitine homeostasis in suckling infants. Biochem. Biophys. Res. Commun. 404:1010-1015.

Lopez, C., M. N. Madec, and R. Jimenez-Flores. 2010. Lipid rafts in the bovine milk fat globule membrane revealed by the lateral segregation of phospholipids and heterogeneous distribution of glycoproteins. Food Chem. 120:22-33.

Lopez, C., and O. Menard. 2011. Human milk fat globules: Polar lipid composition and in situ structural investigations revealing the heterogeneous distribution of proteins and the lateral segregation of sphingomyelin in the biological membrane. Colloids Surf. B Biointerfaces 83:29-41.

Lu, J., E. Antunes Fernandes, A. E. Páez Cano, J. Vinitwatanakhun, S. Boeren, T. van Hooijdonk, A. van Knegsel, J. Vervoort, and K. A. Hettinga. 2013. Changes in milk proteome and metabolome associated with dry period length, energy balance, and lactation stage in postparturient dairy cows. J. Proteome Res. 12:32883296 .

Lu, J., S. Boeren, S. C. de Vries, H. J. F. van Valenberg, J. Vervoort, and K. Hettinga. 2011. Filter-aided sample preparation with di- 
methyl labeling to identify and quantify milk fat globule membrane proteins. J. Proteomics 75:34-43.

McManaman, J. L., and M. C. Neville. 2003. Mammary physiology and milk secretion. Adv. Drug Deliv. Rev. 55:629-641.

Molee, A., N. Duanghaklang, and P. Na-Lampang. 2012. Effects of Acyl-CoA:diacylglycerol acyl transferase 1 (DGAT1) gene on milk production traits in crossbred Holstein dairy cattle. Trop. Anim. Health Prod. 44:751-755.

Palmquist, D. L., K. Stelwagen, and P. H. Robinson. 2006. Modifying milk composition to increase use of dairy products in healthy diets. Anim. Feed Sci. Technol. 131:149-153.

Prema, D., J. L. Pilfold, J. Krauchi, J. S. Church, K. K. Donkor, and B. Cinel. 2013. Rapid determination of total conjugated linoleic acid content in select Canadian cheeses by ${ }^{1} \mathrm{H}$ NMR spectroscopy. J. Agric. Food Chem. 61:9915-9921.

Salzer, U., and R. Prohaska. 2001. Stomatin, flotillin-1, and flotillin-2 are major integral proteins of erythrocyte lipid rafts. Blood 97:1141-1143.

Schennink, A., W. M. Stoop, M. H. P. W. Visker, J. M. L. Heck, H. Bovenhuis, J. J. van der Poel, H. J. F. van Valenberg, and J. A. M. van Arendonk. 2007. DGAT1 underlies large genetic variation in milk-fat composition of dairy cows. Anim. Genet. 38:467-473.

Smith, S. J., S. Cases, D. R. Jensen, H. C. Chen, E. Sande, B. Tow, D. A. Sanan, J. Raber, R. H. Eckel, and R. V. Farese Jr.. 2000. Obesity resistance and multiple mechanisms of triglyceride synthesis in mice lacking Dgat. Nat. Genet. 25:87-90.

Snyers, L., D. Thines-Sempoux, and R. Prohaska. 1997. Colocalization of stomatin (band 7.2b) and actin microfilaments in UAC epithelial cells. Eur. J. Cell Biol. 73:281-285.
Snyers, L., E. Umlauf, and R. Prohaska. 1999. Cysteine 29 is the major palmitoylation site on stomatin. FEBS Lett. 449:101-104

Steiber, A., J. Kerner, and C. L. Hoppel. 2004. Carnitine: A nutritional, biosynthetic, and functional perspective. Mol. Aspects Med. $25: 455-473$

Tukiainen, T., T. Tynkkynen, V. P. Makinen, P. Jylanki, A. Kangas, J. Hokkanen, A. Vehtari, O. Grohn, M. Hallikainen, H. Soininen, M. Kivipelto, P. H. Groop, K. Kaski, R. Laatikainen, P. Soininen, T. Pirttila, and M. Ala-Korpela. 2008. A multi-metabolite analysis of serum by ${ }^{1} \mathrm{H}$ NMR spectroscopy: Early systemic signs of $\mathrm{Al}-$ zheimer's disease. Biochem. Biophys. Res. Commun. 375:356-361.

Umlauf, E., E. Csaszar, M. Moertelmaier, G. J. Schuetz, R. G. Parton, and R. Prohaska. 2004. Association of stomatin with lipid bodies. J. Biol. Chem. 279:23699-23709.

van der Hooft, J. J., V. Mihaleva, R. C. de Vos, R. J. Bino, and J. Vervoort. 2011. A strategy for fast structural elucidation of metabolites in small volume plant extracts using automated MS-guided LC-MS-SPE-NMR. Magn. Reson. Chem. 49:S55-S60.

Vinaixa, M., M. A. Rodriguez, A. Rull, R. Beltran, C. Blade, J. Brezmes, N. Canellas, J. Joven, and X. Correig. 2010. Metabolomic assessment of the effect of dietary cholesterol in the progressive development of fatty liver disease. J. Proteome Res. 9:2527-2538.

Walstra, P., J. T. M. Wouters, and T. J. Geurts. 2006. Dairy Science and Technology. 2nd ed. CRC Press, Boca Raton, FL.

Wiśniewski, J. R., A. Zougman, N. Nagaraj, and M. Mann. 2009. Universal sample preparation method for proteome analysis. Nat. Methods 6:359-362. 